\title{
Acute hemorrhagic edema of young children: a concise narrative review
}

\author{
Elisabetta Fiore - Mattia Rizzi • Giacomo D. Simonetti • \\ Luca Garzoni • Mario G. Bianchetti • Alberto Bettinelli
}

Received: 1 April 2011 /Revised: 13 May 2011 / Accepted: 30 May 2011 / Published online: 15 June 2011

(C) Springer-Verlag 2011

\begin{abstract}
Acute hemorrhagic edema of young children is an uncommon but likely underestimated cutaneous leukocytoclastic vasculitis. The condition typically affects infants 6-24 months of age with a history of recent respiratory illness with or without course of antibiotics. The diagnosis is made in children, mostly nontoxic in appearance, presenting with nonpruritic, large, round, red to purpuric plaques predominantly over the cheeks, ears, and extremities, with relative sparing of the trunk, often with a targetlike appearance, and edema of the distal extremities, ears, and face that is mostly non-pitting, indurative, and tender. In boys, the lesions sometimes involve the scrotum and, more rarely, the penis. Fever, typically of low grade, is often present. Involvement of body systems other than skin is uncommon, and spontaneous recovery usually occurs within 6-21 days without sequelae. In this condition, laboratory tests are non-contributory: total blood cell count is often normal, although leukocytosis and thrombocytosis are sometimes found, clotting studies are normal, erythrocyte
\end{abstract}

\section{E. Fiore $\cdot$ M. Rizzi $\cdot$ L. Garzoni $\cdot$ M. G. Bianchetti} Department of Pediatrics, Mendrisio and Bellinzona, University of Bern,

Bern, Switzerland

G. D. Simonetti

Division of Pediatric Nephrology, University Hospital, Bern, University of Bern,

Bern, Switzerland

\author{
A. Bettinelli \\ Merate-Lecco, Italy \\ M. G. Bianchetti $(\bowtie)$ \\ San Giovanni Hospital, \\ 6500 Bellinzona, Switzerland \\ e-mail: mario.bianchetti@pediatrician.ch
}

Department of Pediatrics, San Leopoldo Mandic Hospital, sedimentation rate and C-reactive protein test are normal or slightly elevated, complement level is normal, autoantibodies are absent, and urinalysis is usually normal. Experienced physicians rapidly consider the possible diagnosis of acute hemorrhagic edema when presented with a nontoxic young child having large targetoid purpuric lesions and indurative swelling, which is non-pitting in character, and make the diagnosis either on the basis of clinical findings alone or supported by a skin biopsy study.

Keywords Annular vasculitis · Child · Cutaneous vasculitis $\cdot$ Henoch-Schönlein syndrome $\cdot$ Leukocytoclastic vasculitis

\section{Background}

Skin leukocytoclastic vasculitis is characterized histologically as an infiltrate composed largely of neutrophils showing fragmentation of nuclei [7]. Clinically, skin leukocytoclastic vasculitis mainly results in purpuric papules recognized as palpable purpura [17]. In rare cases, the lesions have a targetlike appearance and possess a striking resemblance to erythema multiforme. Until this day, there are 20 or less reported cases of adults affected by this annular variant of leukocytoclastic vasculitis [18].

Acute hemorrhagic edema of young children is an annular leukocytoclastic small-vessel vasculitis that was initially described in 1913 in the USA by I. M. Snow [28] and in 1936 in Argentina by M. J. Del Carril [8]. The best descriptions of the condition, however, were made in Germany before the Second World War: in 1939 [24] by H. Seidlmayer (1910-1965) and especially in 1929 by H. Finkelstein (1865-1942) in a textbook [22]. A further important description was made by the French pediatrician 
M. Lelong in 1942 [16]. The disorder, which is considered by some to be a variant of Henoch-Schönlein syndrome, has also been recognized under various terms: cockade (or iris-like) purpura and edema of young children, acute benign cutaneous leukocytoclastic vasculitis of young children, and the eponyms Finkelstein disease, Seidlmayer disease, Finkelstein-Seidlmayer disease, or HenochSchönlein syndrome of early childhood $[5,6,19,23$, 27]. It has been stated that about 300 cases of acute hemorrhagic edema of young children have been reported until 2007 [10]. At least 35 further cases were reported between 2008 and 2010.

\section{Age-gender-trigger}

The age distribution of patients with acute hemorrhagic edema ranges between 2 and 60 months. Eighty percent of the cases occur in children aged 6 to 24 months (median age, approximately 12 months). The male-to-female ratio of the condition, like for Henoch-Schönlein syndrome, approximates 2:1.

Seventy percent of the cases are preceded by an acute illness, most frequently a simple acute respiratory disease, an acute diarrheal disease, or a urinary tract infection. As a consequence, like for typical Henoch-Schönlein syndrome, a seasonal variation with a peak incidence in the cold season has been postulated (but never convincingly proven). Ten percent or less of the cases are preceded by an active immunization: mostly combined vaccinations against diphtheria, pertussis, and tetanus (with or without poliomyelitis) or against measles, mumps and German measles, chickenpox, Haemophilus influenzae type B, or H1N1 immunization.

Paracetamol or, more rarely, either antimicrobials (most frequently an aminopenicillin) or nonsteroidal antiinflammatory agents have been prescribed in a large subset of the children. However, the condition never recurred following re-expositions to these agents, indicating that drugs are not (or very rarely) responsible for this vasculitis.

No association between acute hemorrhagic edema of young children and infections caused by Mycoplasma pneumoniae or A-Streptococcus was found. This is not surprising, considering that these microorganisms mostly cause infections in school-age children [13, 21].

\section{Clinical presentation}

At presentation, almost all patients are nontoxic in appearance (Table 1). Fever, typically of low grade, is present in $50 \%$ of the children. The skin lesions (Fig. 1) develop rapidly over $24-48 \mathrm{~h}$ and include (a) large, round,
Table 1 Distribution of purpuric plaques or edema in children affected with acute hemorrhagic edema of young children

\begin{tabular}{lll}
\hline & Purpuric plaques & Edema \\
\hline Face & ++++ & ++ \\
Ears & +++ & + \\
Trunk & + & + \\
Upper extremities & ++++ & ++ \\
Hands & + & ++ \\
Lower extremities & ++++ & +++ \\
Feet & + & ++ \\
\hline
\end{tabular}

The symbol + denotes an approximate frequency of $20 \%$ or less, ++ $20-40 \%$, +++ $40-60 \%$, and ++++ more than $60 \%$

red to purpuric plaques predominantly over the cheeks, ears, and extremities, with relative sparing of the trunk, often with a target-like appearance and (b) mostly tender non-pitting edema of the distal extremities, ears, and face (Tables 1 and 2).

Pruritus is extremely uncommon (less than $2 \%$ of the cases). Further rather uncommon skin lesions or mucous membrane lesions occur in slightly less than $10 \%$ of the patients: vesicles, bullae, conjunctival injection, and especially oral petechiae.

An involvement of body systems other than skin (and mucous membranes) occurs in less than $5 \%$ of the patients (Table 2): abdominal pain (with or without intestinal bleeding), arthralgia (or arthritis), and thigh hematoma. In boys, the disease sometimes affects the scrotum and, even more rarely, the penis. Contrary to typical HenochSchönlein syndrome, acute kidney disease is rare and mild (seven cases have been so far reported): urinalysis discloses abnormal proteinuria and red blood cells (with or without cell casts), isolated hematuria, or isolated abnormal proteinuria [9]. Blood pressure and renal function are normal in children with abnormal urinalysis, who recover completely within 1-3 weeks without any therapy. Acute febrile non-renal illnesses in which kidney function is preserved may be accompanied by increased urinary protein excretion [2]. Hence, we assume that in acute hemorrhagic edema of young children, a transiently increased urinary protein excretion does not necessarily reflect a renal disease state [2].

\section{Laboratory investigations—biopsy studies}

In acute hemorrhagic edema of young children, routine laboratory tests are nondiagnostic:

- Total blood cell count is often normal, although leukocytosis and thrombocytosis (like in other vasculitides) may be found. 

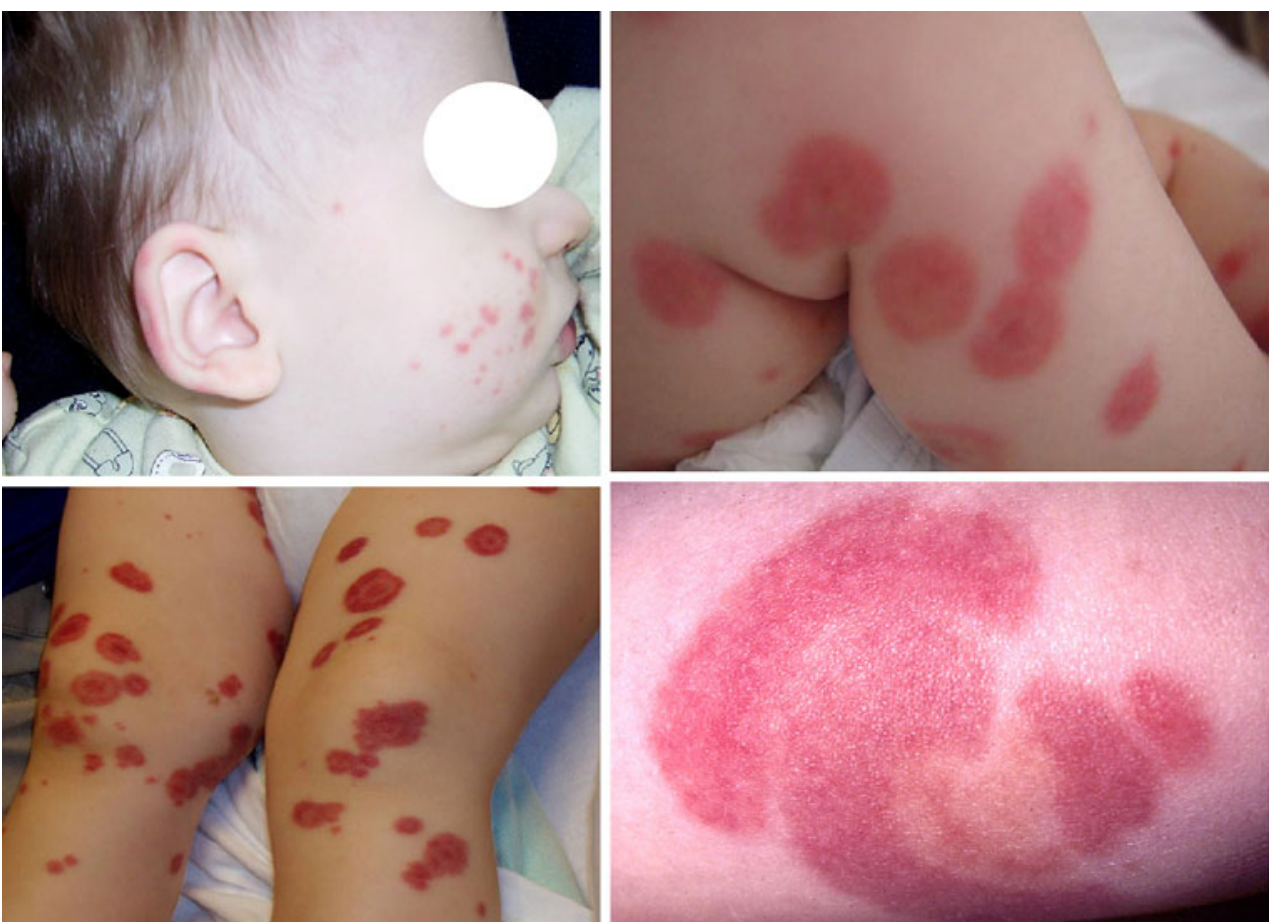

Fig. 1 Characteristic skin lesions in acute hemorrhagic edema of young children: small purpuric lesions over the right cheek and ear (left upper panel), large targetoid lesions on both lower extremities (right upper and left lower panels), and large targetoid lesion (right lower panel)

- C-Reactive protein and erythrocyte sedimentation rates are normal or slightly elevated.

- Circulating complement levels, IgG antineutrophil cytoplasmic autoantibodies, and antinuclear autoantibodies are unremarkable.

- Liver function test results may rarely be slightly elevated.

- Urinalysis results usually are normal.

Histopathological analysis, performed in approximately $50 \%$ of the cases reported in the literature [10], demonstrates a leukocytoclastic vasculitis of the dermal vessels with fibrinoid necrosis, extravasation of red blood cells, and leukocytoclasia (Fig. 2). Direct immunofluorescence examination, performed in approximately one third of the cases with biopsy studies, shows vascular deposits of immunoglobulin A in no more than one quarter of the cases [10].

\section{Differential diagnosis-diagnosis}

The differential diagnosis of acute hemorrhagic edema of young children includes erythema multiforme ${ }^{1}[25,29]$,

\footnotetext{
${ }^{1}$ In erythema multiforme, lesions very often first appear over the dorsa of the hands, with progression in a centripetal fashion to involve the proximal extremities and the trunk. In acute hemorrhagic edema of young children, target-like lesions usually are limited to the limbs and the face together with the presence of extremity edema that does not occur in erythema multiforme.
}

Table 2 Common and uncommon (10\% or less) presentation in acute hemorrhagic edema of young children

\begin{tabular}{|c|c|}
\hline Common & Uncommon \\
\hline \multicolumn{2}{|l|}{ General appearance } \\
\hline Nontoxic & Toxic \\
\hline No fever or low-grade fever & High fever \\
\hline \multicolumn{2}{|l|}{ Skin } \\
\hline $\begin{array}{l}\text { Cockade purpura: head (and ear) }> \\
\text { lower extremities }>\text { upper extremities }> \\
\text { feet and hands }\end{array}$ & $\begin{array}{l}\text { Purpura and edema of scrotum } \\
\text { (or penis) in boys } \\
\text { Fluid-containing lesions }\end{array}$ \\
\hline $\begin{array}{l}\text { Non-pitting, often indurative and painful } \\
\text { edema: lower extremities }>\text { upper } \\
\text { extremities }>\text { head (and ear), feet and hands } \\
\text { Mucous membranes }\end{array}$ & $\begin{array}{l}\text { Urticarial lesions } \\
\text { Pruritus }\end{array}$ \\
\hline No lesions & $\begin{array}{l}\text { Conjunctival injection } \\
\text { Oral petechiae }\end{array}$ \\
\hline \multicolumn{2}{|l|}{ Other systems } \\
\hline None & $\begin{array}{l}\text { Abdominal pain, intestinal } \\
\text { bleeding, intussusception }\end{array}$ \\
\hline & $\begin{array}{l}\text { Arthralgia (less frequently } \\
\text { arthritis) }\end{array}$ \\
\hline & Scrotal involvement ${ }^{\mathrm{a}}$ \\
\hline & Hematoma \\
\hline & Pathological urinalysis ${ }^{\mathrm{b}}$ \\
\hline & Elevated liver enzymes \\
\hline
\end{tabular}

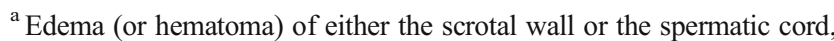
testicular hemorrhage, subcapsular testicular hematoma, epidydimitis or orchitis

${ }^{\mathrm{b}}$ Abnormally increased urinary protein excretion with or without red blood cells and cell casts 


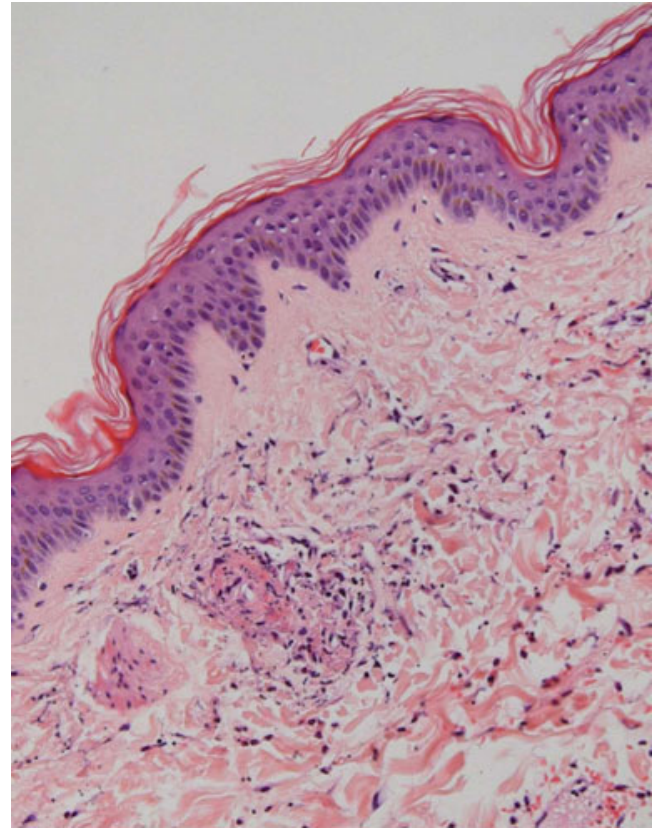

Fig. 2 Skin biopsy specimen showing a characteristic leukocytoclastic vasculitis in a child affected with acute hemorrhagic edema of young children. A postcapillary venule is infiltrated with neutrophils, whose nuclei are in part fragmented and pycnotic. Direct immunofluorescence examination did not disclose vascular deposits of immunoglobulin A (Courtesy of L. Mazzucchelli, MD)

urticaria (skin lesions are markedly pruritic in this condition) with hemorrhagic elements [4], urticaria multiformis [25], drug-induced skin lesions [26], and skin lesions in septicemia: either meningococcal and non-meningococcal Waterhouse-Friderichsen syndrome [12] or, more rarely, skin lesions of Pseudomonas aeruginosa [3] sepsis (Table 3). In addition to erythema multiforme, the most intricate distinction is that between acute hemorrhagic edema of young children and atypical cases (mostly

Table 3 Differential diagnosis of acute hemorrhagic edema of young children

Erythema multiforme
Urticaria multiformis $^{\mathrm{a}}$
Urticaria with hemorrhagic elements
Urticarial vasculitis
Skin lesions in septicemia
Meningococcal and non-meningococcal Waterhouse-Friderichsen
syndrome
Skin lesions of Pseudomonas aeruginosa sepsis
Atypical Henoch-Schönlein syndrome
Abusive bruises

${ }^{a}$ Both the term urticaria multiformis and urticaria mutiforme are used in the literature, but only the latin term urticaria multiformis is grammatically correct children aged 2-4 years) of Henoch-Schönlein syndrome [17], which initially present either without involvement of the lower extremities or both with the distinctive rash as well as with edema of the hands, feet, or face [15, 20]. Finally, the presumptive clinical diagnosis of abusive bruises has been sometimes made in patients affected with acute hemorrhagic edema of young children [14]. In clinical practice, the diagnostic criteria given in the box are useful [27]. The diagnosis is made either on the basis of clinical findings or supported by a skin biopsy study. From a dermatologic point of view, any dermatosis suspected of being a vasculitis should undergo biopsy. On the other hand, pediatricians tend to diagnose Henoch-Schönlein syndrome and, subsequently, acute hemorrhagic edema of young children as well, on the basis of clinical manifestations. At our institution, the diagnosis is made without biopsy study on a clinical basis only.

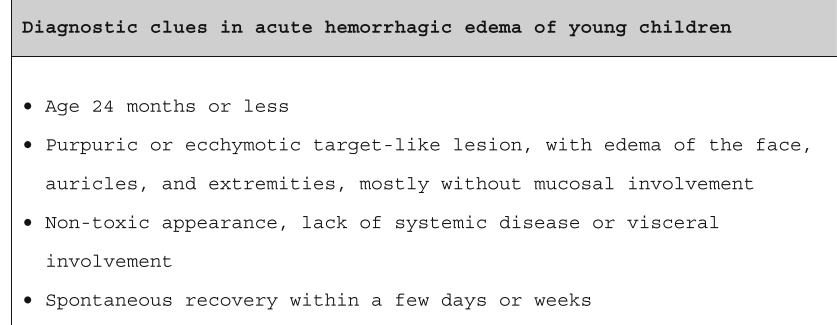

\section{Acute hemorrhagic edema of young children—a separate disorder}

Some investigators believe that acute hemorrhagic edema of young children is a variant of Henoch-Schönlein syndrome [17]. This assumption is supported among others by a report documenting the concomitant appearance of acute hemorrhagic edema and Henoch-Schönlein syndrome in a sister and a brother aged 16 and 43 months, respectively [11]. Cases also exist of children, who have findings overlapping between acute hemorrhagic edema of young children and Henoch-Schönlein syndrome [15, 20]. The distinct features in acute hemorrhagic edema have been related to a possible gravity-dependent development of skin lesions, with a predilection to the buttocks and lower extremities in typical Henoch-Schönlein cases. Since infants with acute hemorrhagic edema spend most of their time lying down, gravity cannot be considered a factor. Another factor that may affect the distribution of the skin lesions is the abundance of blood supply: it has been therefore postulated that the proportionally larger head and face with a corresponding increase in blood supply in infants would render them more susceptible to facial purpura $[15,20]$. 
On the other side, most authors currently agree that there are sufficient clinical and prognostic differences to consider acute hemorrhagic edema a separate entity, including the very different skin features and especially the failure to detect depositions of immunoglobulin $\mathrm{A}$ in most biopsy specimens. As a consequence, we consider that acute hemorrhagic edema of young children and typical Henoch-Schönlein are related but clinically separate vasculitides [10].

\section{Course-management}

In the patients, the eruptions spontaneously disappear without sequelae within 2 to 60 days: in $80 \%$ of cases, within 6 to 21 days. No effective management currently exists, and systemic steroids do not alter the disease course. In a large subset of the patients, antimicrobials are initially given but are discontinued after obtaining negative culture results. Explanation and reassurance of the family regarding the self-limited and benign nature of acute hemorrhagic edema of young children and particularly frequent observation by the caregiver are of paramount importance. Children with tender skin lesions are prescribed paracetamol or a nonsteroidal anti-inflammatory agent. Acute hemorrhagic edema of young children rarely presents with pruritus: nonetheless, anti-histamines are widely prescribed $[1,10]$, mainly to give the impression that something is done (ut aliquid fieri videatur et ab patiente non revocatur).

Conflict of interest The authors have no conflict of interest to disclose.

\section{References}

1. Alp H, Artaç H, Alp E, Reisli I (2009) Acute infantile hemorrhagic edema: a clinical perspective (report of seven cases). Marmara Med J 22:155-161

2. Ariceta G (2011) Clinical practice: proteinuria. Eur J Pediatr 170:15-20

3. Bagel J, Grossman ME (1986) Subcutaneous nodules in Pseudomonas sepsis. Am J Med 80:528-529

4. Bailey E, Shaker M (2008) An update on childhood urticaria and angioedema. Curr Opin Pediatr 20:425-430

5. Baselga E, Drolet BA, Esterly NB (1997) Purpura in infants and children. J Am Acad Dermatol 37:673-707

6. Carder KR (2005) Hypersensitivity reactions in neonates and infants. Dermatol Ther 18:160-175
7. Carlson JA (2010) The histological assessment of cutaneous vasculitis. Histopathology 56:3-23

8. Del Carril MJ, Díaz Sobillo I, Vidal J (1936) Edema agudo hemorrágico en un lactante. Prensa Med Argent 23:1719-1722

9. Fiore E, Bernasconi M, Simonetti GD, Rizzi M, Bianchetti MG (2008) Kidney disease in acute hemorrhagic edema of young children. Turk J Pediatr 50:512

10. Fiore E, Rizzi M, Ragazzi M, Vanoni F, Bernasconi M, Bianchetti MG, Simonetti GD (2008) Acute hemorrhagic edema of young children (cockade purpura and edema): a case series and systematic review. J Am Acad Dermatol 59:684-695

11. Gattorno M, Picco P, Vignola S, Di Rocco M, Buoncompagni A (1999) Brother and sister with different vasculitides. Lancet 353:728

12. Jacobs RF, Hsi S, Wilson CB, Benjamin D, Smith AL, Morrow R (1983) Apparent meningococcemia: clinical features of disease due to Haemophilus influenzae and Neisseria meningitidis. Pediatrics 72:469-472

13. Jaggi P, Shulman ST (2006) Group A streptococcal infections. Pediatr Rev 27:99-105

14. Kos L, Shwayder T (2006) Cutaneous manifestations of child abuse. Pediatr Dermatol 23:311-320

15. Legrain V, Lejean S, Taïeb A, sGuillard JM, Battin J, Maleville J (1991) Infantile acute hemorrhagic edema of the skin: study of ten cases. J Am Acad Dermatol 24:17-22

16. Lelong $M$, Joseph $R$, Charousset X (1942) L'oèdème aigu hémorragique de la peau du nourrisson. Arch Fr Pediatr 1:41-45

17. McCarthy HJ, Tizard EJ (2010) Clinical practice: diagnosis and management of Henoch-Schönlein purpura. Eur J Pediatr 169:643-650

18. Meissner M, Kaufmann R (2009) Annular leukocytoclastic vasculitis after the administration of an amlodipine generic. J Eur Acad Dermatol Venereol 23:238-239

19. Miner Kanflanka I, Vivanco López A, Muñoz Bernal JA, Landa Maya J, Albisu Andrade Y (2004) Edema agudo hemorrágico del lactante. Revisión bibliográfica. Bol Soc Vasco-Nav Pediatr 37:13-16

20. Nussinovitch M, Prais D, Finkelstein Y, Varsano I (1998) Cutaneous manifestations of Henoch-Schönlein Purpura in young children. Pediatr Dermatol 6:426-428

21. Principi N, Esposito S (2002) Mycoplasma pneumoniae and Chlamydia pneumoniae cause lower respiratory tract disease in paediatric patients. Curr Opin Infect Dis 15:295-300

22. Rosenstern I (1956) Heinrich Finkelstein, 1865-1942. J Pediatr 49:499-503

23. Salman SM, Kibbi AG (2002) Vascular reactions in children. Clin Dermatol 20:11-15

24. Seidlmayer H (1939) Die frühinfantile, postinfektiöse KokardenPurpura. Z Kinderheilkd 61:217-255

25. Shah KN, Honig PJ, Yan AC (2007) "Urticaria multiforme": a case series and review of acute annular urticarial hypersensitivity syndromes in children. Pediatrics 119:e1177-e1183

26. Shin HT, Change MW (2002) Drug eruptions in children. Curr Probl Dermatol 14:153-182

27. Smitt JH, Vermeer MH, Faber WR (2002) Acute hemorrhagic edema of infancy. Clin Dermatol 20:2-3

28. Snow IM (1913) Purpura, urticaria and angioneurotic edema of the hands and feet in a nursing baby. JAMA 61:18-19

29. Villiger RM, von Vigier RO, Ramelli GP, Hassink RI, Bianchetti MG (1999) Precipitants in 42 cases of erythema multiforme. Eur J Pediatr 158:929-932 